\title{
Randomized trial on fluorides and sealant for fissure caries prevention
}

\author{
Bao Ying LIU' ${ }^{1}$, Edward Chin Man LO ${ }^{1}$, Chun Hung CHU ${ }^{1}$, Huan Cai LIN ${ }^{2}$ \\ ${ }^{1}$ Faculty of Dentistry, University of Hong Kong, Hong Kong SAR, ${ }^{2}$ School of \\ Stomatology, Sun Yat-sen University, Guangzhou, China
}

\section{Correspondence:}

Prof. Edward C.M. Lo

3/F, Prince Philip Dental Hospital, 34 Hospital Road, Hong Kong

E-mail: edward-lo@hku.hk

Tel: 852-2859 0292

Fax: 852-2858 7874

\section{Running title:}

Topical fluorides and sealant in caries prevention

Based on a thesis submitted to the Faculty of Dentistry, University of Hong Kong, in partial fulfillment of the requirements for the PhD degree. 


\begin{abstract}
To investigate how effective topical fluorides are in preventing fissure caries, a randomized controlled trial with parallel groups was conducted. A total of 501 children (1539 molars, 3078 sites), mean age 9.1 years, who had at least one sound permanent first molar with deep fissures or fissures with signs of early caries were recruited. They were randomly allocated into four groups: (1) resin sealant, single placement; (2) 5\% NaF varnish, semi-annual application; (3) 38\% silver diamine fluoride (SDF) solution, annual application; and (4) placebo control. Follow-up examinations were conducted every 6 months by a masked examiner. After 24 months, 485 children (97\%) were examined. Proportions of pit/fissure sites with dentin caries in the sealant, $\mathrm{NaF}$, SDF, and control groups, were $1.6 \%, 2.4 \%, 2.2 \%$, and $4.6 \%$ respectively. A multi-level logistic regression analysis accounting for the effects of data clustering and confounding factors showed that fissures in any of the three treatment groups had significantly lower risks of carious cavity development into dentin than controls $(\mathrm{p}<0.05)$. Conclusion: placement of resin sealant, semi-annual application of NaF varnish, and annual application of SDF solution, are all effective in preventing pit and fissure caries in permanent molars. (ClinicalTrials.gov number, CT01446107).
\end{abstract}

\title{
Key words:
}

Dental caries, pit and fissure, preventive dentistry, fluoride, resin sealant, children 


\section{Introduction}

Dental caries is common among school children worldwide (Petersen, 2003) and in the permanent dentition it occurs mostly in molars (Batchelor and Sheiham, 2004; Sheiham and Sabbah, 2010). This poses a significant problem in populous developing countries, such as China (Hu et al., 2011; Lo et al., 1999). There is a great need to implement effective programs to prevent caries in the pits and fissures of the permanent molars of school children. In the rural or less developed areas where resources and dental care services are limited, innovative and cost-effective preventive methods are called for.

Systematic review has shown that dental sealant is effective for the prevention of fissure caries (Ahovuo-Saloranta et al., 2008). However, the good performance of sealants depends on high-quality placement aided by electrically powered devices (Beauchamp et al., 2008). Therefore, using this method in areas where access to dental clinics is limited may be problematic.

Sodium fluoride $(\mathrm{NaF})$ varnish has been shown to be effective in preventing dental caries in children and adolescents (Marinho et al., 2002; Marinho, 2009). However, few clinical studies have been conducted specifically to assess its effectiveness in preventing caries in the pits and fissures of permanent molars (Hiiri et al., 2010).

A recent systematic review found silver diamine fluoride (SDF) solution to be effective in preventing and arresting dental caries in young children (Rosenblatt et al., 2009). So far only one study reported on its use to prevent caries in permanent first molars (Llodra et al., 2005).

The aim of this study was to investigate the effectiveness of resin fissure sealant, $\mathrm{NaF}$ varnish and SDF solution in preventing pit and fissure caries in permanent molars of schoolchildren. The null hypothesis was that all three treatments had no caries prevention effect compared to a placebo control.

\section{Materials and methods}

A randomized clinical trial with parallel groups was implemented in April 2008 in a suburb of Guangzhou in southern China. There was no systemic fluoridation there while approximately $90 \%$ of the toothpastes on sale contained fluoride. Ethical approval was granted by the University of Hong Kong (www.ClinicalTrials.gov \#NCT01446107).

Children studying in grades 2 or 3 in the four largest primary schools of the study site were invited. Children with parental consent were clinically examined by one trained dentist in the schools. Generally healthy children who had at least one sound permanent first molar with deep fissures or fissures with signs of early (enamel) caries viewed wet, opacities and discoloration, similar to ICDAS code 2 (Ismail et al., 2007) were included. Molars with caries into dentin and fissures with potential dentin caries indicated by DIAGNOdent (KaVo, Germany) readings $\geq 40$ (Lussi et al., 2004) were excluded. 
Each included molar was assessed at two sites (upper molar: mesial pit/fossa and distalpalatal groove; lower molar: occlusal fissure and buccal pit/groove). The recorded status included fissure morphology (deep/shallow), sign of early caries (yes/no), and DIAGNOdent reading. Information on the child's toothbrushing habits, snacking habits, and dental visit history was collected through a questionnaire.

An assistant, using computer-generated random numbers, allocated the children individually into four groups: (1) sealant - placement of resin sealant (Clinpro Sealant, 3M ESPE, St. Paul, USA) with no replacement; (2) NaF - semi-annual application of a 5\% NaF varnish (Duraphat, Colgate-Palmolive Ltd, Waltrop, Germany); (3) SDF annual application of a 38\% SDF solution (Saforide, Toyo Seiyaku Kasei Co. Ltd., Osaka, Japan); (4) placebo control - annual application of water. Treatments were applied by another dentist according to group allocation.

In the sealant group, the tooth was isolated with cotton rolls. Pits and fissures were etched with 37\% phosphoric acid for 15 seconds, washed with water, and then dried with gently blown air. The sealant was applied and then light-cured. Complete setting and retention of sealant was confirmed before the child left. In the NaF varnish and the SDF solution groups, the tooth was isolated with cotton rolls. The topical fluoride agent was painted on the pits/fissures using a small disposable brush. The child was instructed not to drink or eat for half an hour.

Status of the molars, including sealant retention and development of caries into dentin, ICDAS codes 4-6 (Ismail et al., 2007), was assessed every 6 months by the same blinded examiner using disposable mouth-mirrors attached to an intra-oral LED light and CPI probes. Sites with sealant fully retained were regarded as sound. The primary study outcome was carious cavity development into dentin. A 10\% random sample was reexamined during every examination to monitor intra-examiner reproducibility. Carious cavities in the study molars were treated with placement of ART restorations.

In sample size calculation, an $80 \%$ survival (no dentin caries) of the molars receiving fissure sealant was anticipated, and a 10\% absolute difference in caries incidence between groups was regarded as clinically significant. Using a 5\% statistical significance level and an $80 \%$ power, calculated by using $\mathrm{K}^{*} \mathrm{C}$ cross-tabulation in SamplePower 2.0, 950 teeth were required. This number was multiplied by [1+(m-1)ICC] to adjust for the clustering effect of several teeth within one child (Murray et al., 2004). The intraclass correlation (ICC) was estimated to be 0.2 and three molars were expected in each child (i.e., $\mathrm{m}=3$ ). With an anticipated $10 \%$ drop-out rate, the numbers of teeth and children required at baseline were 1478 and 493, respectively.

\section{Data analysis}

Chi-square test was used to compare the caries incidence of the four groups using the statistical software SPSS 19.0 (SPSS Inc., Chicago, USA). To study the effects of various factors and to account for clustering of data, a multi-level logistic regression analysis was

performed using generalized estimating equation (GEE) modeling with the SAS 9.2 
software (SAS Institute Inc., Cary, USA). Outcome was recorded at the tooth-site level, and a two-level structure (level 1 - pit/fissure; level 2 - child) was adopted. The dependent variable was the presence of dentin caries at the 24-month examination. Independent variables included those at the subject- and tooth-level: treatment (sealant, $\mathrm{NaF}$, SDF), gender (boy/girl), grade (2/3), snacking (frequent or not), tooth-brushing (frequent or not), baseline dental visit history (yes/no), baseline $\mathrm{dmft}$ score, molar location (upper/lower); as well as variables at the site-level: early caries at baseline (present/absent), DIAGNOdent reading (high/low), and fissure morphology (shallow/deep). Interaction effects between the independent variables were considered. Exchangeable and independent correlation structure of the clustering of sites in child was also assessed, and the model yielding the highest QIC value was selected as the final model.

\section{Results}

Among the 1000 invited children, 499 were excluded because they did not fulfill the inclusion criteria (Fig. 1). A total of 3078 pit/fissure sites (1539 molars) in 501 children (50\% boys), mean age 9.1 years, were included. In total, 485 children with 1491 molars and 2982 sites (97\%) were followed for 24 months. Eighteen sites in 3 children were excluded because the involved teeth had orthodontic bands on. The only complaint received was a transient bitter taste associated with SDF, and no adverse side-effects were observed.

Regarding distribution of subject- and site-level factors in the four groups at baseline (Table 1), proportionally more children in the sealant group than in other groups had visited a dentist or took snacks once a day or less $(\mathrm{p}<0.05)$. There were no significant differences in other factors.

Intra-examiner reliability was excellent (kappa $>0.9$ ). At the $24-$-month examination, $46 \%$ of the sealants were partially or fully retained. Proportions of pit/fissure sites with dentin caries were not significantly different $(\mathrm{p}>0.05)$ in the sealant, $\mathrm{NaF}$, and SDF groups, $1.6 \%, 2.4 \%$, and $2.2 \%$ respectively (Table 2 ). The percentage of sites with dentin caries in the control group, $4.6 \%$, was significantly higher than those in the three treatment groups $(\mathrm{p}=0.002)$. The site-level prevented fractions (PF) were $65 \%, 48 \%$, and $52 \%$ for sealant, NaF varnish, and SDF solution, respectively.

The GEE logistic regression analysis results showed that sealant placement $(\mathrm{OR}=0.32$, $\mathrm{p}=0.017)$, NaF varnish $(\mathrm{OR}=0.43, \mathrm{p}=0.033)$, and $\mathrm{SDF}$ solution $(\mathrm{OR}=0.44, \mathrm{p}=0.029)$ were protective factors while lower molar $(\mathrm{OR}=2.43, \mathrm{p}=0.009)$, early caries at baseline $(\mathrm{OR}=3.09, \mathrm{p}<0.001)$, high baseline DIAGNOdent reading $(\mathrm{OR}=4.85, \mathrm{p}<0.001)$, and baseline dental visit experience $(\mathrm{OR}=2.19, \mathrm{p}=0.016)$ were risk factors for the development of dentin caries (Table 3).

\section{Discussion}


In this study, effectiveness of the treatments was studied at the pit/fissure level. The 24month incidence rates of dentin caries in the three treatment groups were lower than that in the control group. Thus, the null hypothesis was rejected. This is supported by the multi-level logistic regression analysis when the effects of data clustering and selected confounding factors were accounted for.

In this study, the prevented fraction (PF) of NaF varnish application after 24 months at the tooth-level was 39\%. This is similar to the 38\% PF found in a comparable study by Bravo et al. (1996). Hardman et al. (2007) did not find significant caries reduction when $\mathrm{NaF}$ varnish was applied onto molars in school children, and they suggested the poor response and low caries incidence rates of the study sample as possible explanations. It has been suggested that subjects should be restricted from drinking and eating for half an hour (Adair, 2006) or 4 hours (Hawkins et al., 2003) after fluoride varnish application. In this study, due to practical reasons (children would return home for meal after school), the children were asked not to eat for at least half an hour. It is not clear to what extent this affects the effectiveness.

The tooth-level PF of the SDF solution application in this study, 41\%, is lower than the $\mathrm{PF}$ of $65 \%$ found in a study conducted in Cuba (Llodra et al., 2005). This may be due to the difference in application frequency, once vs. twice per year, between this and that study.

In this study, the tooth-level PF of resin sealant 24 months after placement was $60 \%$, which is lower than those reported in most of the previous studies (approximately 80\%) (Ahovuo-Saloranta et al., 2008). This may be related to the lower sealant retention rate in this study compared to other studies, 46\% vs. 80\% (Ahovuo-Saloranta et al., 2008; Muller-Bolla et al., 2006). Most likely, the field setting and the use of portable dental equipment in this study was less than optimal for good placement of resin sealant. Difficulty in moisture control during the sealant placement was sometimes encountered, which may have affected the retention of the resin-based fissure sealants, a main factor for its effectiveness. Under more optimal working conditions, a higher sealant retention rate and a higher PF would be expected (Gooch et al., 2009).

The incidence of fissure caries in the control group in this study is in line with the recently reported national average prevalence of dental caries in 12-year-old children in China (Hu et al., 2011), but it is low compared to the results of previous studies conducted among high caries risk populations (Bravo et al., 1996; Songpaisan et al., 1995). This low 24-month caries incidence may be partially explained by the slower dental caries progression rate nowadays (Whelton, 2004). Similarly low levels of fissure caries incidence are also observed in schoolchildren at similar ages in other countries (Parner et al., 2007; Rugarabamu et al., 2002). In addition, the oral health education delivered to all of the children and the popularity of fluoridated toothpaste in the area of this study may have had an effect on decreasing caries development in the study population. This may in turn have led to a reduced difference in caries development among the four study groups. 
Multilevel modeling using a Bayesian approach for survival analysis has been used to analyze hierarchical clustered interval-censored data from longitudinal clinical studies (Harkanen, et al., 2002; Wong et al., 2005). In survival analysis, event development is linked with time. For events that take a long time to develop, such as carious cavity development into dentin, substantial bias may arise when using survival analysis if the observation period is relatively short and the event occurrence rates are low for the early portions of the time scale. Since the caries progression rate in this study is low, the advantage of using survival analysis may not be achieved. Therefore, multilevel logistic regression modeling, a method that uses single-time-point outcome data, was adopted.

In this study, although some of the background factors were not balanced at the baseline, the possible interactions among these factors together with the factor of treatment were considered in the multivariate GEE logistic modeling. After using the GEE model to adjust for the effects of data clustering and confounding factors, the factor of treatment remained in the final model. The effectiveness of the three study treatments in preventing pit and fissure caries in permanent molars was confirmed.

In the final model, it was found that study teeth with early caries at baseline, as indicated by clinical signs or a DIAGNOdent reading $\geq 15$, were more likely to develop dentin caries after 24 months. The lower molars in this study were also at a higher risk than the upper molars. This is in agreement with other epidemiological findings (Batchelor and Sheiham, 2004). These molars are at a higher risk of developing caries and warrant a higher priority for prevention (Beauchamp et al., 2008). In this study, children who had a dental visit history at baseline developed more dental caries during the 24-month period than those who did not. These children probably had a higher past caries experience which is commonly considered as a risk indicator for new caries development (Bader et al., 2008; Sarmadi et al., 2009).

The 2-year results of this clinical trial provide some support to the use of topical fluoride applications for prevention of caries in the permanent molars of school children, given that it is their major dental disease. In areas or populations where resources and availability of dental care service do not present a major problem, resin sealant placement may be the preventive treatment of choice among school children. However, in less developed areas where economic consideration and resource limitations are more influential in decision making, it may not be possible. Application of NaF varnish or SDF solution onto the pits and fissures of the molars may be considered as an alternative preventive method to placement of fissure sealant. Topical fluoride application is technically simple, does not require powered dental equipment, and may be performed by trained auxiliary health personnel. These are advantages for its use in dental public health program or community projects for the prevention of dental caries in school children, especially those living in places where there are shortages of dental personnel and necessary equipment for the placement of fissure sealant. Before making recommendations on these new alternative methods for fissure caries prevention, more information is needed from studies on longer-term outcomes and economic evaluation, such as their cost-effectiveness. 
Based on the 24-month results and within the limitations of this study, it is concluded that the three preventive methods, placement of resin sealant, semi-annual application of $\mathrm{NaF}$ varnish, and annual application of SDF solution, are effective in preventing pit and fissure caries in permanent molars. Furthermore, their effectiveness is not significantly different.

\section{Acknowledgement}

This study was supported by Hong Kong Research Grants Council (\#HKU/771207M). Authors had no conflict of interest.

\section{References}

Adair SM (2006). Evidence-based use of fluoride in contemporary pediatric dental practice. Pediatric Dent 28:133-42.

Ahovuo-Saloranta A, Hiiri A, Nordblad A, Mäkelä M, Worthington HV (2008). Pit and fissure sealants for preventing dental decay in the permanent teeth of children and adolescents. Cochrane Database Syst Rev 4: CD001830.

Bader JD, Perrin NA, Maupome G, Rush WA, Rindal BD (2008). Exploring the contributions of components of caries risk assessment guidelines. Community Dent Oral Epidemiol 36: 357-362.

Batchelor PA, Sheiham A (2004). Grouping of tooth surfaces by susceptibility to caries: a study in 5-16 year-old children. BMC Oral Health 4:2 (doi:10.1186/1472-6831-4-2).

Beauchamp J, Caufield PW, Crall JJ, et al. (2008). Evidence-based clinical recommendations for the use of pit-and-fissure sealants: a report of the American Dental Association Council on Scientific Affairs. J Am Dent Assoc 139:257-268.

Bravo M, Llodra JC, Baca P, Osorio E (1996). Effectiveness of visible light fissure sealant (Delton) versus fluoride varnish (Duraphat): 24-month clinical trial. Community Dent Oral Epidemiol 24:42-46.

Gooch BF, Griffin SO, Gray SK, et al. (2009). Preventing dental caries through schoolbased sealant programs, updated recommendations and reviews of evidence. $J$ Am Dent Assoc 140:1356-1365.

Hardman MC, Davies GM, Duxbury JT, Davies RM (2007). A cluster randomised controlled trial to evaluate the effectiveness of fluoride varnish as a public health measure to reduce caries in children. Caries Res 41:371-376.

Harkanen T, Larmas MA, Virtanen JI, Arjas E (2002). Applying modern survival analysis methods to longitudinal dental caries studies. J Dent Res 81:144-148.

Hawkins R, Locker D, Noble J, Kay EJ (2003). Prevention Part 7: professionally applied topical fluorides for caries prevention. Br Dent J 195:313-317.

Hiiri A, Ahovuo-Saloranta A, Nordblad A, Mäkelä M (2010). Pit and fissure sealants versus fluoride varnishes for preventing dental decay in children and adolescents. Cochrane Database Syst Rev 3: CD003067.

Hu D, Hong X, Li X (2011). Oral health in China - trends and challenges. Int J Oral Sci 3:7-12. 
Ismail AI, Sohn W, Tellez M, et al. (2007). The international caries detection and assessment system (ICDAS): an integrated system for measuring dental caries. Community Dent Oral Epidemiol 35:170-178.

Llodra JC, Rodriguez A, Ferrer B, Menardia V, Ramos T, Morato M (2005). Efficacy of silver diamine fluoride for caries reduction in primary teeth and first permanent molars of schoolchildren: 36-month clinical trial. J Dent Res 84(8): 721-724.

Lo ECM, Holmgren CJ, Hu DY, Wan HC (1999). Dental caries status and treatment needs of 12-13 year-old children in Sichuan Province, Southwestern China. Community Dent Health 16:114-116.

Lussi A, Hibst R, Paulus R (2004). DIAGNOdent: an optical method for caries detection. J Dent Res 83(Spec):80-83.

Marinho VC (2009). Cochrane reviews of randomized trials of fluoride therapies for preventing dental caries. Eur Arch Paediatr Dent 10: 183-191.

Marinho VC, Higgins JP, Logan S, Sheiham A (2002). Fluoride varnishes for preventing dental caries in children and adolescents. Cochrane Database Syst Rev 3: CD002279.

Muller-Bolla M, Lupi-Pegurier L, Tardieu C, Velly AM, Antomarchi C (2006). Retention of resin-based pit and fissure sealants: A systematic review. Community Dent Oral Epidemiol 34:321-336.

Murray DM, Varnell SP, Blitstein JL (2004). Design and analysis of group-randomized trials: a review of recent methodological developments. Am J Public Health 94: 42332.

Parner ET, Heidmann JM, Vaeth M, Poulsen S (2007). Surface-specific caries incidence in permanent molars in Danish children. Eur J Oral Sci 115:491-496.

Petersen PE (2003). The World Oral Health Report 2003: continuous improvement of oral health in the 21st century - the approach of the WHO Global Oral Health Programme. Community Dent Oral Epidemiol 31(Suppl 1):3-24.

Rosenblatt A, Stamford TCM, Niederman R (2009). Silver diamine fluoride: a caries “silver-fluoride bullet”. J Dent Res 88:119-125.

Rugarabamu PGN, Poulsen S, Masalu JPR (2002). A longitudinal study of occlusal caries among schoolchildren in Dar es Salaam, Tanzania. Community Dent Oral Epidemiol 30:47-51.

Sarmadi R, Gabre P, Gahnberg L (2009). Strategies for caries risk assessment in children and adolescents at public dental clinics in a Swedish county. Int J Paediatr Dent 19:135-140.

Sheiham A, Sabbah W (2010). Using universal patterns of caries for planning and evaluating dental caries. Caries Res 44: 141-150.

Songpaisan Y, Bratthall D, Phantumvanit P, Somridhivej Y (1995). Effects of glass ionomer cement, resin-based pit and fissure sealant and HF applications on occlusal caries in a developing country field trial. Community Dent Oral Epidemiol 23:25-29.

Whelton H (2004). Overview of the impact of changing global patterns of dental caries experience on caries clinical trials. J Dent Res 83(Spec):29-34.

Wong MC, Lam KF, Lo EC (2005). Bayesian analysis of clustered interval-censored data. J Dent Res 84:817-21. 
Figure 1 Subjects flow until 24 months in this study ( $\mathrm{n}=$ number of subject, $\mathrm{N}=$ number of teeth; $2 \mathrm{~N}=$ number of fissure sites)

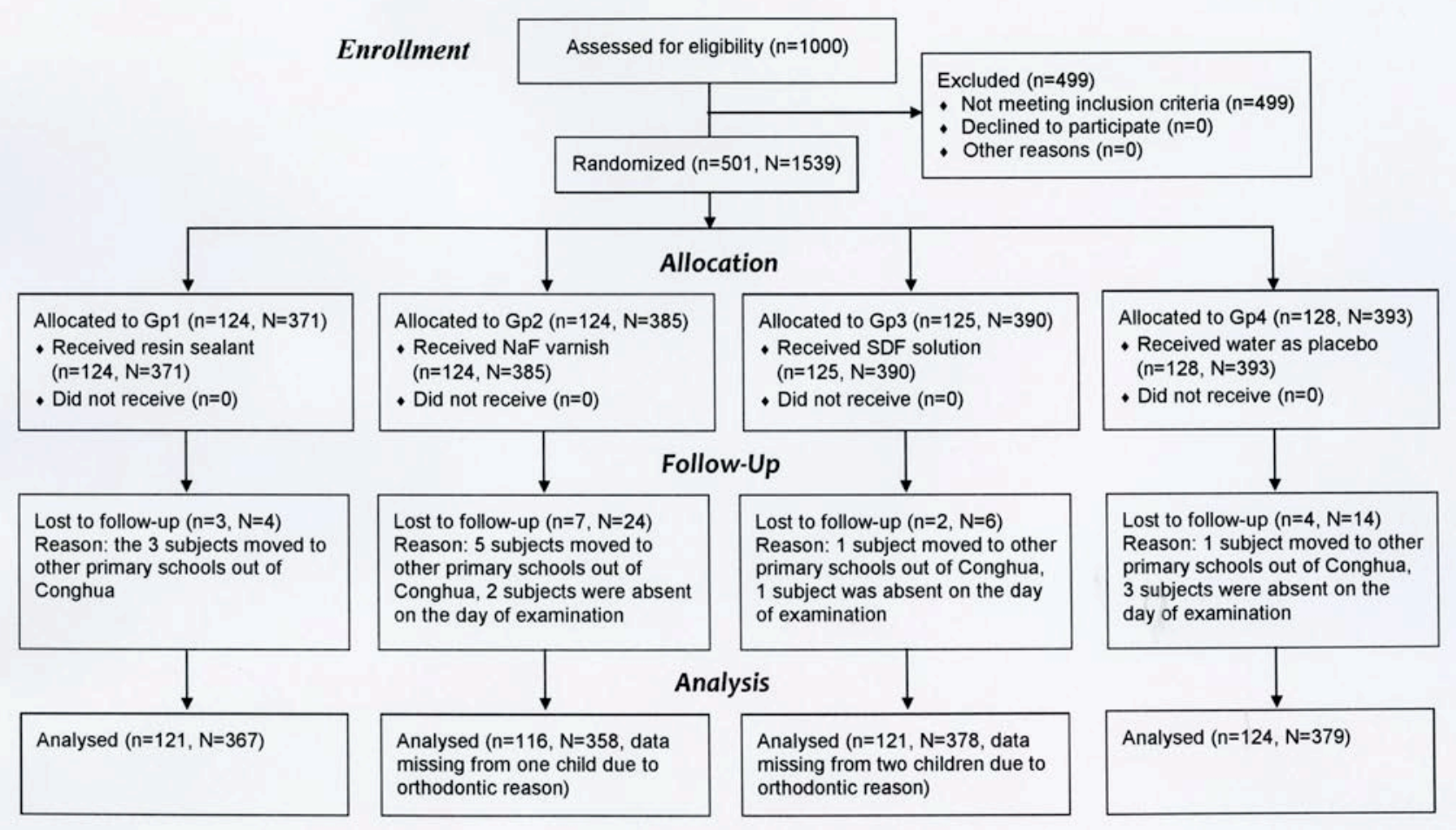


Table 1 Distribution of the study children and tooth sites in the four groups according to different factors at the baseline

\begin{tabular}{|c|c|c|c|c|c|}
\hline \multirow{2}{*}{ Factors } & \multicolumn{4}{|c|}{ Group } & \multirow{2}{*}{ p-value } \\
\hline & Sealant & $\mathrm{NaF}$ & SDF & Control & \\
\hline \multicolumn{6}{|l|}{ Subject-level } \\
\hline Gender & & & & & 0.150 \\
\hline - boy & $56(45 \%)$ & $54(44 \%)$ & $69(55 \%)$ & $69(54 \%)$ & \\
\hline - girl & $68(55 \%)$ & $70(56 \%)$ & $56(45 \%)$ & $59(46 \%)$ & \\
\hline Grade & & & & & 0.686 \\
\hline - grade 2 & $63(51 \%)$ & $57(46 \%)$ & $54(43 \%)$ & $60(47 \%)$ & \\
\hline - grade 3 & $61(49 \%)$ & $67(54 \%)$ & $71(57 \%)$ & $68(53 \%)$ & \\
\hline Dental visit history & & & & & 0.024 \\
\hline - yes & $60(48 \%)$ & $74(60 \%)$ & $80(64 \%)$ & $84(66 \%)$ & \\
\hline- no & $64(52 \%)$ & $50(40 \%)$ & 45 (36\%) & $44(34 \%)$ & \\
\hline Snacking habit & & & & & 0.005 \\
\hline - once a day or less & $108(87 \%)$ & $86(69 \%)$ & $95(76 \%)$ & $91(71 \%)$ & \\
\hline - twice or more a day & $16(13 \%)$ & 38 (31\%) & $30(24 \%)$ & 37 (29\%) & \\
\hline Tooth brushing habit & & & & & 0.560 \\
\hline - once a day or less & $54(44 \%)$ & $64(52 \%)$ & $55(44 \%)$ & $60(47 \%)$ & \\
\hline - twice or more a day & $70(56 \%)$ & $60(48 \%)$ & $70(56 \%)$ & $68(53 \%)$ & \\
\hline \multicolumn{6}{|l|}{ Site-level } \\
\hline Fissure morphology & & & & & 0.175 \\
\hline - shallow & $110(15 \%)$ & $124(16 \%)$ & $133(17 \%)$ & $104(13 \%)$ & \\
\hline - deep & $632(85 \%)$ & $646(84 \%)$ & $647(83 \%)$ & $682(87 \%)$ & \\
\hline Early caries & & & & & 0.939 \\
\hline - yes & 257 (35\%) & 267 (35\%) & $280(36 \%)$ & $272(35 \%)$ & \\
\hline- no & 485 (65\%) & $503(65 \%)$ & $500(64 \%)$ & $514(65 \%)$ & \\
\hline DIAGNOdent reading & & & & & 0.508 \\
\hline-16 to 39 & $291(39 \%)$ & $299(39 \%)$ & $281(36 \%)$ & 308 (39\%) & \\
\hline - 15 or lower & $451(61 \%)$ & $471(61 \%)$ & 499 (64\%) & 478 (61\%) & \\
\hline Site location & & & & & 0.224 \\
\hline - upper molar & 338 (46\%) & $348(45 \%)$ & $372(48 \%)$ & $392(50 \%)$ & \\
\hline - lower molar & 404 (54\%) & $422(55 \%)$ & $408(52 \%)$ & $394(50 \%)$ & \\
\hline
\end{tabular}


Table 2. New dentine caries in the four study groups at the subject-, tooth-, and site-levels and prevented fractions at the 24-month follow up.

\begin{tabular}{lcccc}
\hline & Sealant & NaF & SDF & Control \\
\hline No. with new caries & 9 & 15 & 15 & 21 \\
- Subject & 11 & 16 & 17 & 28 \\
- Tooth & 12 & 17 & 17 & 35 \\
- Fissure site & & & & \\
& & & & \\
Caries incidence (\%) & 7.4 & 12.8 & $12.2^{\text {a }}$ & 16.9 \\
- Subject* & $3.0^{\mathrm{a}}$ & $4.4^{\mathrm{a}}$ & $4.4^{\mathrm{a}}$ & $7.4^{\mathrm{b}}$ \\
- Tooth & $1.6^{\mathrm{c}}$ & $2.4^{\mathrm{c}}$ & $2.2^{\mathrm{c}}$ & $4.6^{\mathrm{d}}$ \\
- Fissure site & & & & \\
& & & 41 & --- \\
Prevented Fraction (\%) $^{\#}$ & 60 & 41 & 52 & -- \\
- Tooth & 65 & 48 & & \\
- Fissure site & & & & \\
\hline
\end{tabular}

Chi-square test, ${ }^{*} \mathrm{p}>0.05,{ }^{*} \mathrm{a}<\mathrm{b}, \mathrm{p}=0.04{ }^{*}{ }^{*}<\mathrm{d}, \mathrm{p}=0.002$ 
Table 3. Final model of the multi-level GEE logistic regression $\left(\mathrm{n}_{\text {subject }}=482\right.$, $\mathrm{N}_{\text {fissure }}=2964$ )

\begin{tabular}{|c|c|c|c|c|c|c|c|}
\hline \multirow[t]{2}{*}{ Factors } & \multirow[t]{2}{*}{ B } & \multirow[t]{2}{*}{ S.E. } & \multirow{2}{*}{$\begin{array}{l}\text { Chi- } \\
\text { square }\end{array}$} & \multirow{2}{*}{$\begin{array}{c}\mathrm{p}- \\
\text { value }\end{array}$} & \multirow{2}{*}{$\begin{array}{l}\text { Exp } \\
\text { (B)* }\end{array}$} & \multicolumn{2}{|c|}{$\begin{array}{l}\text { 95\% C.I. for } \\
\text { Exp (B) }\end{array}$} \\
\hline & & & & & & Lower & Upper \\
\hline DIAGNOdent reading 16-39 & 1.58 & 0.33 & 22.87 & $<0.001$ & 4.85 & 2.54 & 9.27 \\
\hline With early caries at baseline & 1.13 & 0.30 & 13.96 & $<0.001$ & 3.09 & 1.71 & 5.58 \\
\hline Lower molar & 0.89 & 0.34 & 6.83 & 0.001 & 2.43 & 1.25 & 4.72 \\
\hline $\begin{array}{l}\text { Dental visit history at } \\
\text { baseline }\end{array}$ & 0.78 & 0.33 & 5.76 & 0.016 & 2.19 & 1.15 & 4.15 \\
\hline Study group & & & 8.23 & 0.042 & & & \\
\hline - SDF vs. Control & -0.82 & 0.39 & 4.56 & 0.029 & 0.44 & 0.21 & 0.93 \\
\hline - NaF vs. Control & -0.84 & 0.39 & 4.76 & 0.033 & 0.43 & 0.21 & 0.92 \\
\hline - Sealant vs. Control & -1.12 & 0.47 & 5.72 & 0.017 & 0.32 & 0.13 & 0.82 \\
\hline Intercept & -5.66 & 0.45 & & $<0.001$ & & & \\
\hline
\end{tabular}

* $\operatorname{Exp}(\mathrm{B})=$ Odds ratio $(\mathrm{OR})$ 